\title{
Comparison of intravenous digital subtraction cineangiocardiography with conventional contrast ventriculography for the determination of the left ventricular volume at rest and during exercise
}

\author{
B. Birchler, O. M. Hess, T. Murakami, P. Niederer, M. Anliker and H. P. Krayenbuehl \\ Institute of Biomedical Engineering, Swiss Federal Institute of Technology Zurich and Department of \\ Medicine, Medical Policlinic, Cardiology, University Hospital Zurich, Switzerland
}

KEY WORDS: digital subtraction cineangiocardiography; contrast ventriculography; left ventricular volume; supine bicycle exercise; ejection fraction.

Left ventricular volumes were determined by means of digital subtraction cineangiocardiography (DSA) which was performed in the right anterior oblique projection after contrast agent injection into the superior vena cava. Monoplane end-diastolic ( $E D V$ ), end-systolic volumes (ESV), and ejection fraction (EF) were calculated using the 'area-length' method and were compared with the same parameters obtained by conventional left ventricular cineangiocardiography. A first group of 20 patients was studied at rest and a second group of 10 patients during bicycle exercise at a work load of 64 watts during 2 min, by DSA and conventional cineangiocardiography. Three different subtraction modes were evaluated: (1) mask mode subtraction (MMS), (2) time interval difference (TID) method and (3) a combination of MMS and TID called $M M S+T I D$ method. With the MMS method good correlations were obtained for EDV, ESV and EF at rest $(r>0.91)$ and during exercise $(r>0.91)$. The TID method showed only moderate correlations for patients at rest $(r>0.86)$ and during exercise $(r>0.79)$. Similar results as with MMS were achieved by the combined method $(M M S+T I D)$ at rest $(r>0.91)$ and during exercise $(r>0.91)$. Interobserver variability indicated a high reproducibility for all methods except for TID during exercise.

It is concluded that DSA is an accurate technique for left ventricular volume determination not only at rest but also during exercise. The best results are obtained with MMS or MMS+TID methods, while left ventricular contour detection is easier and more convenient with MMS TID.

Intravenous digital subtraction angiocardiography (DSA) has been shown ${ }^{[1-7]}$ to be a reliable tool for assessing left ventricular function in man. Due to the fact that contrast material is injected through a intravenous catheter, this technique while still invasive, is more convenient to the patient than conventional left ventricular angiocardiography. However, the low contrast of these images has to be enhanced by means of digital image processing to obtain a sufficiently contrasted angiocardiogram. The most widely used technique for studying patients at rest is mask mode subtraction ${ }^{[8-12]}$

Received for publication on 28 December 1984 and in revised form 26 February 1985

This work was suported by grant 3.804 .0 .82 from the Swiss National Science Foundation and by a grant of the EMDO foundation.

Address for correspondence: B. Birchler, MSEE, and O. M. Hess, MD, Med. Policlinic, Cardiology, University Hospital, Raemistr. 100, CH-8091 Zurich, Switzerland. because of its simplicity and its similarity to conventional angiocardiography.

In patients with coronary artery disease left ventricular function is studied preferably during exercise because wall motion abnormalities, which often manifest themselves only under exercise conditions are of diagnostic importance to detect ischaemic areas at risk. Digital subtraction angiocardiography offers the possibility to study patients not only at rest but also during exercise $\mathrm{e}^{[13.14]}$. However, a validation of this technique with contrast ventriculography has not been published so far. Because suppression of respiration during exercise is often difficult in many patients, motion artifacts and ambiguous contours appear in subtracted images due to misregistration of the mask and the contrast containing frames. This is particularly true for mask mode imaging. Therefore, the time-interval-difference technique with a short temporal separation ( $20 \mathrm{~ms}$ to $80 \mathrm{~ms}$ ) 
of the mask and the contrast containing frame has been proposed as a method to detect left ventricular function at rest $^{[3]}$ as well as during exercise ${ }^{[13]}$. Thus, the purpose of the present study was to validate digital subtraction angiocardiography for assessing global left ventricular function in patients with coronary artery disease at rest and during exercise using three different subtraction modes. In contrast to most other digital subtraction angiocardiographic techniques where subtractions are performed from video recordings, we used digital subtraction of conventionally obtained cineangiographic frames (50 frames $\mathrm{s}^{-1}$ ) after intravenous injection of the contrast agent. With this particular data carrier, high temporal and spatial resolution was achieved. As method of reference, conventional left ventricular cineangiocardiography was used.

\section{Patients and angiographic examination}

Thirty-three patients ( 31 male, 2 female, 27-65 years of age) underwent left ventricular cineangiocardiography for diagnostic purposes. Informed consent was obtained from all patients. Coronary artery disease was diagnosed in 29 patients. Four patients had normal coronary arteries. One patient was subsequently excluded from the study because of premature ventricular beats during left ventricular angiocardiography. Two patients were unable to suppress respiration during intravenous administration of the contrast agent resulting in severe motion artifacts which allowed no proper background subtraction. As a consequence, the study was performed in 20 patients at rest (group 1) and in 10 patients during exercise (group 2). The patients of group 1 were studied first by conventional left ventricular cineangiocardiography in the right anterior oblique projection (RAO) with injection of $45 \mathrm{ml}$ Urographin $76 \%\left(12 \mathrm{ml} \mathrm{s}^{-1}\right)$ into the left ventricle with a $8 \mathrm{~F}$-pigtail catheter. The angiocardiogram was recorded on cinefilm by means of a Siemens Angioscop system at a frame rate of 50 frames $\mathrm{s}^{-1}$. Simultaneously, a standard lead of the ECG and a numerical code which appeared also on the cinefilm were recorded on an oscillograph (Electronics for Medicine VR12) at a paper speed of $250 \mathrm{~mm} \mathrm{~s}^{-1}$.

After the first angiogram, an interval of $15 \mathrm{~min}$ was allowed for dissipation of the haemodynamic effects of the contrast agent. Then, a second injection of $45 \mathrm{ml}$ Urographin $\left(15 \mathrm{ml} \mathrm{s}^{-1}\right)$ was performed into the superior vena cava. The entire sequence starting one or two heart cycles before the injection and ending after the contrast agent had passed through the left ventricle was recorded in RAO projection on cinefilm with the same framerate of 50 frames $\mathrm{s}^{-1}$. During the passage of the contrast agent from the vena cava to the left ventricle, the patients were asked to hold their breath to avoid misregistration and patient motion.

The second group was studied during bicycle exercise at a work load of 50 or $75 \mathrm{~W}$ for $2 \mathrm{~min}$ (mean work load $64 \mathrm{~W}$ ). At the end of the exercise period, conventional RAO left ventricular cineangiocardiography was carried out first by injection of $60 \mathrm{ml}$ urographin with a flow rate of 16 to $18 \mathrm{ml} \mathrm{s}^{-1}$. Because the exercise test was performed twice and the patients had to suppress respiration during the injection the exercise test was carried out at a low or moderate work load. Again, after the first angiogram, an interval of $15 \mathrm{~min}$ was allowed for dissipation of the haemodynamic effects of the contrast agent. Then, bicycle exercise test was repeated at the same work load and duration as before and $60 \mathrm{ml}$ urographin (flow rate $17 \mathrm{ml} \mathrm{s}^{-1}$ ) were injected into the superior vena cava. Because the apneic phase was too long for some patients, especially during exercise, slight degradation of the recorded images by motion artifacts was unavoidable in these instances. No patient experienced angina pectoris during the exercise test.

At the end of the procedure, a metal sphere of known diameter $(6 \mathrm{~cm})$ was filmed for calibration purposes.

\section{Digital image processing}

The cinefilm was automatically scanned on a computer-assisted (DEC PDP-11/45) image processing system (Fig. 1). The observer entered the numbers of the desired frames for digitization at the computer terminal. The cinefilm was then transported under computer control using a modified Vanguard M-35 projector for film display. Digitization was carried out on a high resolution image dissector camera (EMR Photoelectric/ Schlumberger, ODD 658A). Individual image points were digitized with 12 bits resolution and stored in two semiconductor memories of $512 \times 512$ pixels after logarithmic transformation. Up to four frames representing end-diastole and end-systole, respectively, of consecutive heart cycles were digitized and averaged (Fig. 2, F) to reduce image noise. From the averaged image the 


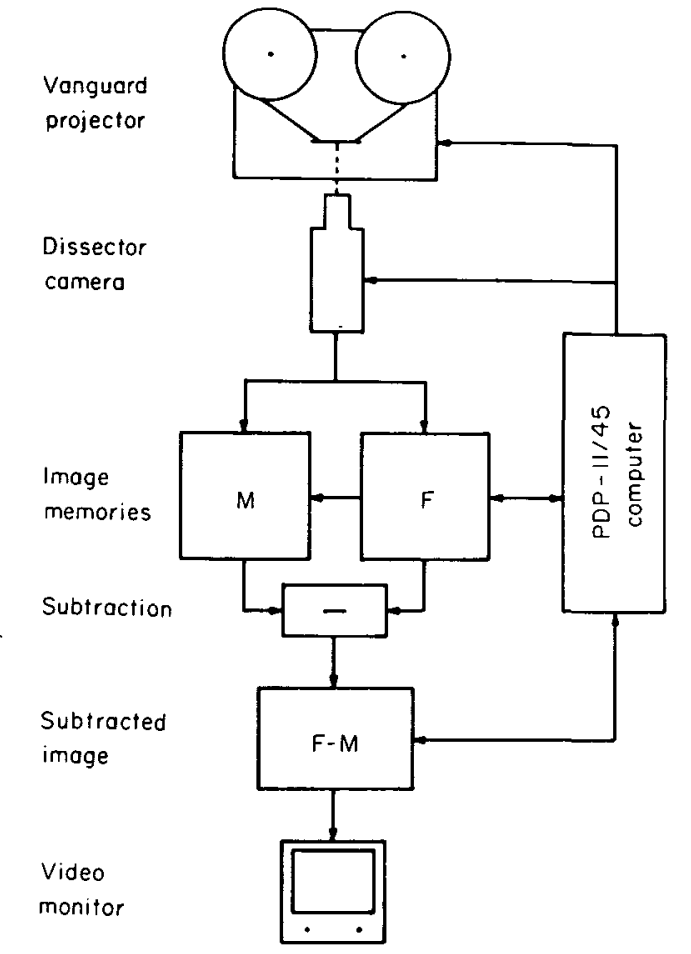

Figure I Image processing hardware: The 35-mm cinefilm is transported on a Vanguard projector. Digitization is performed by a slow scanning camera. A mask image (M) and a iodinated frame $(\mathrm{F})$ are logarithmically transformed and stored in $512 \times 512$ pixel matrices. The subtracted image is displayed on a high resolution video monitor. The operator only has to enter some patient data and the frame numbers to digitize. Then, film transportation, digitization and the subtraction procedure is performed automatically by computer control.

mask (M1 or M2) was subtracted to increase image contrast. After subtraction, the image was linearly amplified to extend the brightness over the whole dynamic range of the image processing system.

Three different subtraction modes were tested to determine the most accurate technique for volume determination with conventional angiocardiograms as the reference method (Fig. 2).

\section{MASK MODE SUBTRACTION (MMS ${ }^{[8-12]}$ )}

The subtraction mask was usually taken before the agent was injected into the patient at the beginning of the film sequence (Fig. 2, M1). In some patients the mask was taken at the end of the film sequence when the contrast agent had passed the left ventricle (M2) because of motion artifacts (e.g. cough) during the lung passage.
TIME INTERVAL DIFFERENCE (TID ${ }^{[1,12]}$ )

TID imaging is based on the same algorithm as the mask mode subtraction except that the time between the mask and the opacified image is very short, namely in the range of 20 to $80 \mathrm{~ms}$ to minimize motion artifacts (Fig. 2). As a result, in the TID mode rapidly moving objects are visualized whereas stationary and slowly moving parts are subtracted and hence not seen. TID images were usually noisier than MMS images because averaging of multiple frames had to be avoided to obtain optimal sharpness of the subtracted image.

TID AND MMS MODE (MMS + TID)

A combination of the previously described two methods was used to obtain adequate information for subsequent boundary detection. Therefore, TID mode was used to determine the rapidly moving sections of the left ventricular wall and MMS was used to complete boundary detection.

\section{Contour detection and volume calculation}

The left ventricular silhouette was traced by a semi-automatic contour detection algorithm on the high-resolution monitor. Since noise and motion artifacts often lead to a poor image quality, a fully automatic contour detection of the ventricle is not reliable for clinical routine. Therefore, boundary detection was performed on the monitor using a light-pen and a cursor. The observer had to select a random number of boundary points which were connected by a cubic spline function ${ }^{[15]}$. The boundary was approximated as close as possible by adding or removing points. Usually, a set of 15 to 20 points resulted in an acceptable approximation of the left ventricular boundary. This method was used for MMS, TID and in an extended implementation also for MMS + TID: first, a set of edge points was determined using the TID image; then, the TID was replaced by the MMS image and the previously selected TID boundary points were superimposed and served as an aid to complete contour detection.

After determination of the left ventricular contour at end-diastole and end-systole, the left ventricular volume was calculated using the 'arealength' method ${ }^{[16]}$ for monoplane angiograms. Left ventricular ejection fraction was estimated from the end-diastolic minus end-systolic volume divided by the end-diastolic volume $\times 100$. All parameters were determined by two independent observers (Obl and $\mathrm{Ob} 2)$ for conventional angio- 


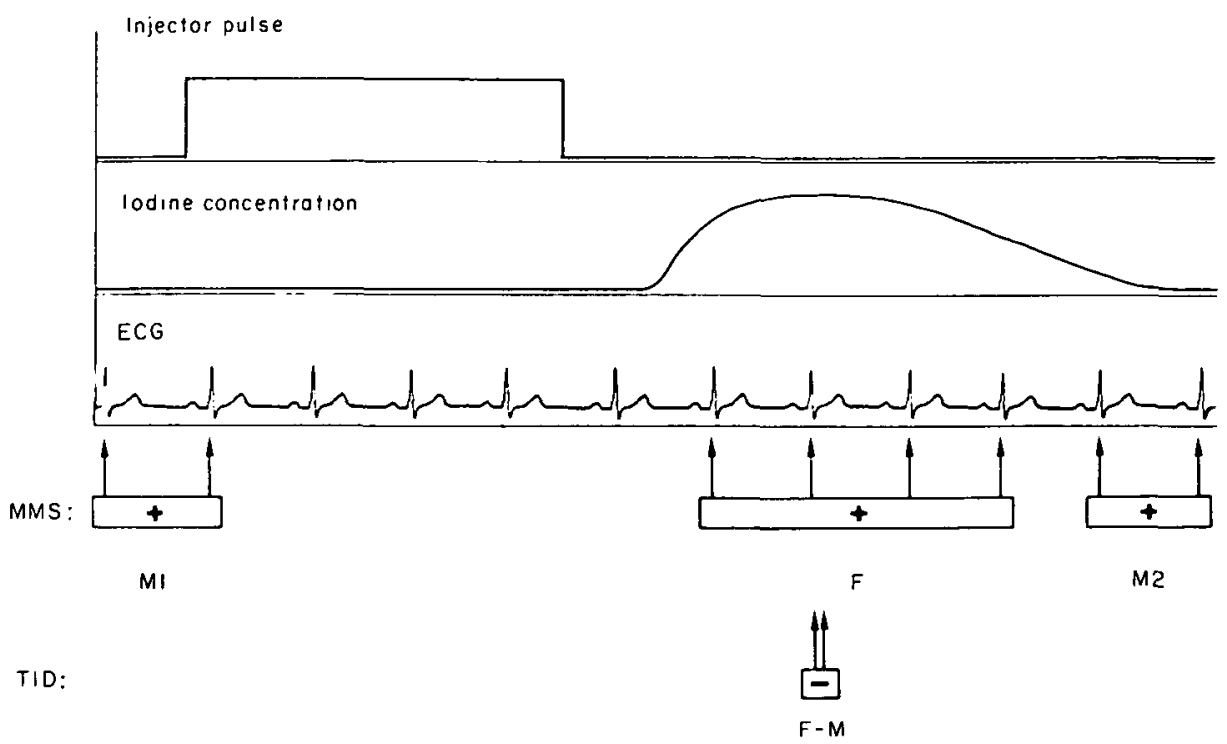

Figure 2 Image subtraction modes: After injection of the contrast material (top line) into the superior vena cava, it needs a certain time (about 6-8 s) to reach the left ventricle (concentration curve). For mask mode subtraction (MMS), a noniodinated mask (M1 or M2) is subtracted from a iodinated frame (F) to remove stationary information and enhance contrast. The end-diastolic and end-systolic frames are identified using the ECG curve. Noise can be suppressed by averaging several frames of subsequent heart cycles. Taking the mask after the contrast has passed through the left ventricle (M2) instead of the pre-injection mask Ml may be of advantage to correct for motion artifacts during lung passage of the iodine material. The subtraction algorithm is the same for time interval difference imaging (TID) but the time between the two frames is very short (20 to $80 \mathrm{~ms}$ ) for imaging fast moving contours.

grams as well as for MMS, TID and MMS + TID intravenous angiograms. Accuracy and interobserver variability between digital subtraction and conventional angiocardiography were assessed by linear regression analysis. The regression line is determined to go through the origin. The correlation coefficient $(r)$ and the standard error of estimate of the mean (SEE; \%) were calculated for both observers and all methods.

\section{Results}

Illustrative digitized angiograms of a patient at rest (Fig. 3) and during exercise (Fig. 4) are shown using the MMS (left hand panels) and TID method (right hand panels).

\section{HAEMODYNAMIC MEASUREMENTS}

Heart rate, left ventricular end-diastolic and peak systolic pressure were not significantly different between conventional and intravenous angiocardiograms (Table 1). Heart rate and enddiastolic pressure were significantly higher during exercise than at rest. Peak systolic pressure was slightly but not significantly higher during exercise than at rest.

VALIDATION OF VOLUME DETERMINATION (FIGS 5, 6; TABLES 2,3)

MMS subtraction mode

At rest and during exercise high correlation

Table 1 Haemodynamic measurements. Heart rate (HR) and end-diastolic pressure (EDP) were significantly higher during exercise than at rest $\left({ }^{*} P<0.001,{ }^{* *} P<0.01\right)$. The increase in peak systolic pressure (PSP) was not significant during exercise

\begin{tabular}{|c|c|c|c|c|}
\hline & \multicolumn{2}{|c|}{ LVA } & \multicolumn{2}{|c|}{ DSA } \\
\hline & rest & exercise & rest & exercise \\
\hline $\begin{array}{l}\text { HR (beats min }{ }^{-1} \text { ) } \\
\text { EDP }(\mathrm{mmHg}) \\
\text { PSP }(\mathrm{mmHg})\end{array}$ & $\begin{array}{l}69^{*} \\
16 \cdot 9^{*} \\
134\end{array}$ & $\begin{array}{l}94 \\
27 \cdot 6 \\
148\end{array}$ & $\begin{array}{l}69^{*} \\
18 \cdot 8^{* *} \\
140\end{array}$ & $\begin{array}{l}97 \\
27 \cdot 6 \\
145\end{array}$ \\
\hline
\end{tabular}



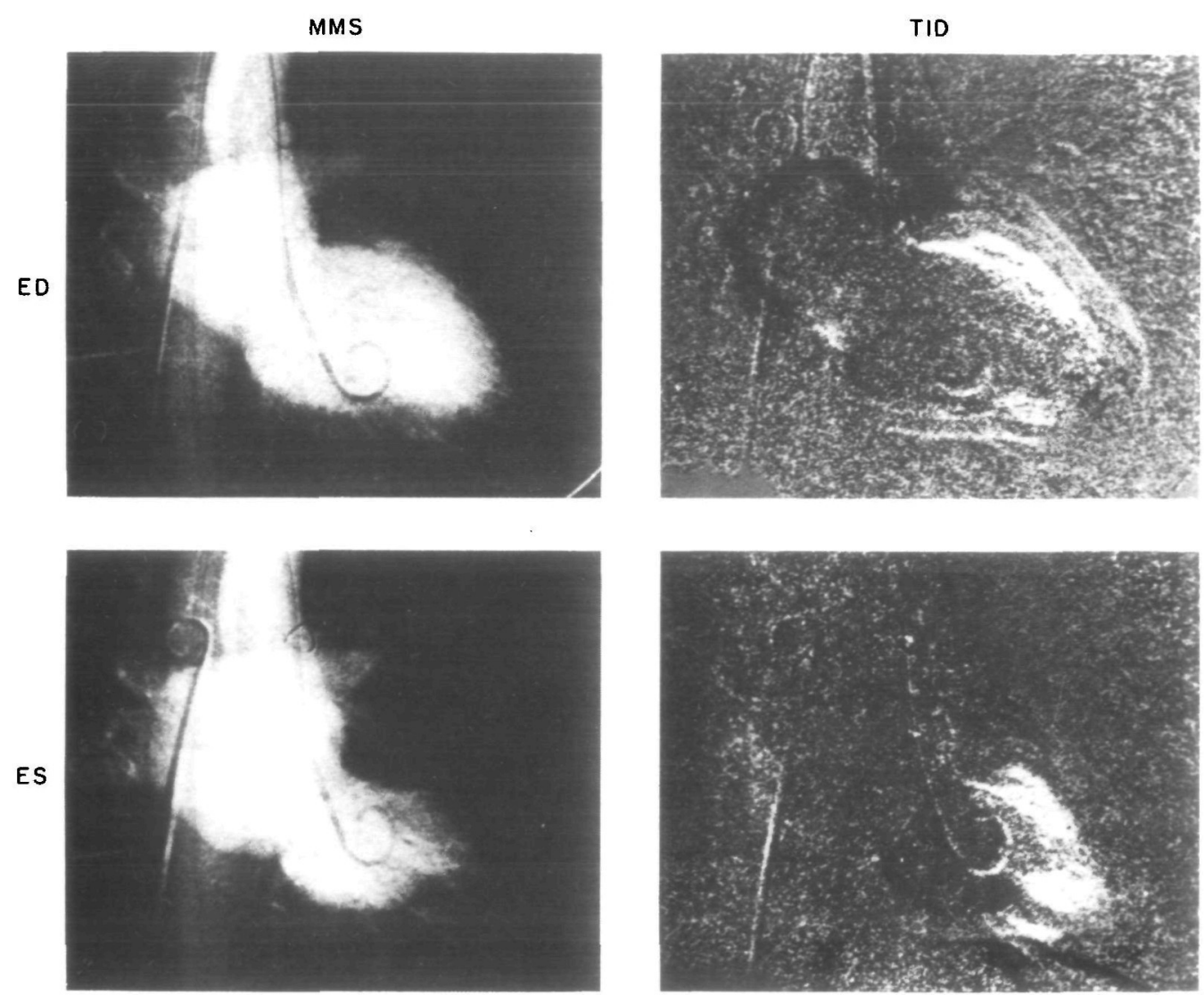

Figure 3 Subtraction images for a patient at rest (ED - end-diastole, ES - end-systole, MMS - mask mode subtraction, TID - time interval difference method). Note that the end-systolic left ventricular contour is slightly larger in the TID than MMS image due to the fact that filling has occurred between the subtracted ( $\approx$ end-systole) and the iodinated frame.

coefficients $(r>0.911)$ were obtained for both observers. The SEE was usually low (SEE $<15 \%$ of the mean value of the reference method); it was highest for the end-systolic volumes.

\section{TID subtraction mode}

Correlation coefficients were lower for TID than the other two subtraction modes. At rest the differences were small compared to the MMS mode but during exercise the correlation coefficient for the ejection fraction was considerably lower (not significant) for the TID than the MMS or MMS + TID mode. The SEE was highest for the TID mode at rest and during exercise and exceeded $20 \%$ for ejection fraction during exercise.

\section{$M M S+T I D$ subtraction mode}

Correlation coefficients at rest and during exercise were comparable to the MMS mode but usually slightly higher. The SEE was generally small; as with MMS it was highest for end-systolic volumes.

INTEROBSER VER VARIABILITY (FIGS 7, 8; TABLES 2, 3)

Interobserver variability for conventional angiocardiographic volume determination was excellent (end-diastolic volume at rest $r=0.995$, during exercise $r=0.978$; end-systolic volume at rest $r=0.988$, during exercise $r=0.991$; ejection fraction at rest $r=0.972$, during exercise $r=0.990$ ) and SEE was very low $(\mathrm{SEE}<9 \%)$.

\section{MMS subtraction mode}

The correlation coefficient between the two observers was high for resting data $(r>0.930)$ and for end-systolic volume and ejection fraction during exercise $(r>0.948)$. However, the correlation coefficient was moderate for end-diastolic volume $(r=0.819)$ during exercise. The SEE was usually low $(\mathrm{SEE}<13 \%)$ at rest and during exercise. 

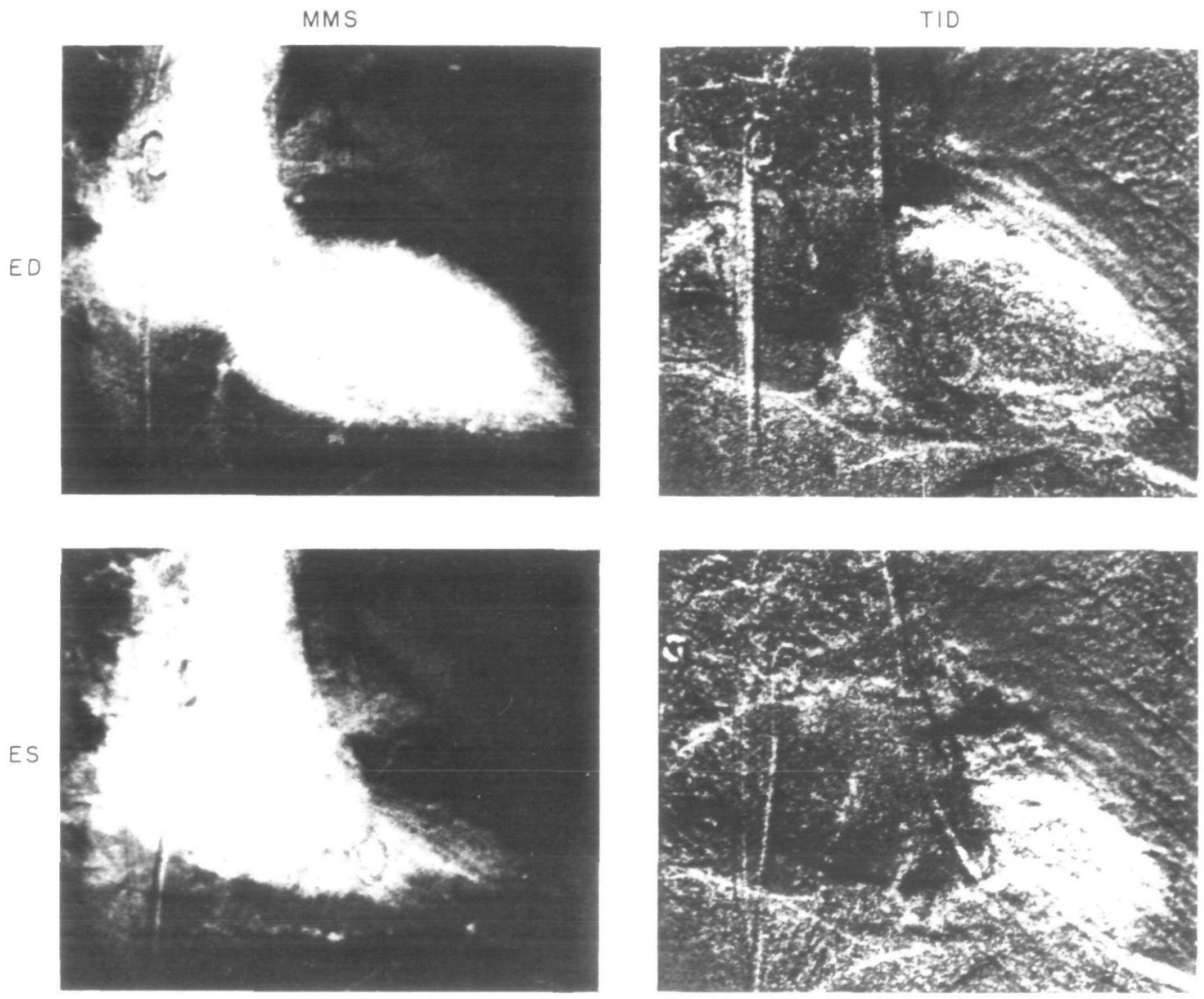

Figure 4 Subtraction images for a patient during exercise (abbreviations as in Fig. 3).

\section{TID subtraction mode}

The correlation coefficient was good for enddiastolic volume at rest and during exercise $(r>0.969 ; \mathrm{SEE}=6 \%)$ and moderate for endsystolic volume and ejection fraction during exercise with a large SEE.

\section{MMS+TID subtraction mode}

High correlation coefficients were observed for all data at rest and during exercise $(r>0.954$; SEE $<14 \%$ ).

\section{Discussion}

Digital subtraction angiocardiography has been shown by several groups to be a reliable technique for left ventricular volume determination at rest $^{[1-7]}$. Several subtraction modes have been used so far and data acquisition was usually performed using on-line video recordings. Most authors reported (Table 4) good correlation coefficients for left ventricular volume determination ( $r$ ranging from 0.82 to 0.98 ) and for ejection fraction ( $r$ ranging from 0.81 to 0.97 ) at rest. Since temporal ( 25 or 30 frames $s^{-1}$ ) and spatial resolution of the video-based systems can be a limiting factor for assessment of left ventricular volumes, we decided to use cineangiocardiography for high temporal (50 frames $\mathrm{s}^{-1}$ ) and spatial (cinefilm) resolution. This is especially important during exercise when heart rate is increased. A sampling rate of 25 frames $\mathrm{s}^{-1}$ might be too low and a considerable error might result in the determination of end-systole and end-diastole.

One goal of our study was to evaluate the accuracy of digital subtraction cineangiocardiography for estimation of left ventricular volumes during bicycle exercise, because this technique has not been validated with contrast cineventriculography under exercise conditions. Recently, a comparison of digital subtraction angiocardiography with radionuclide ventriculography during exercise 

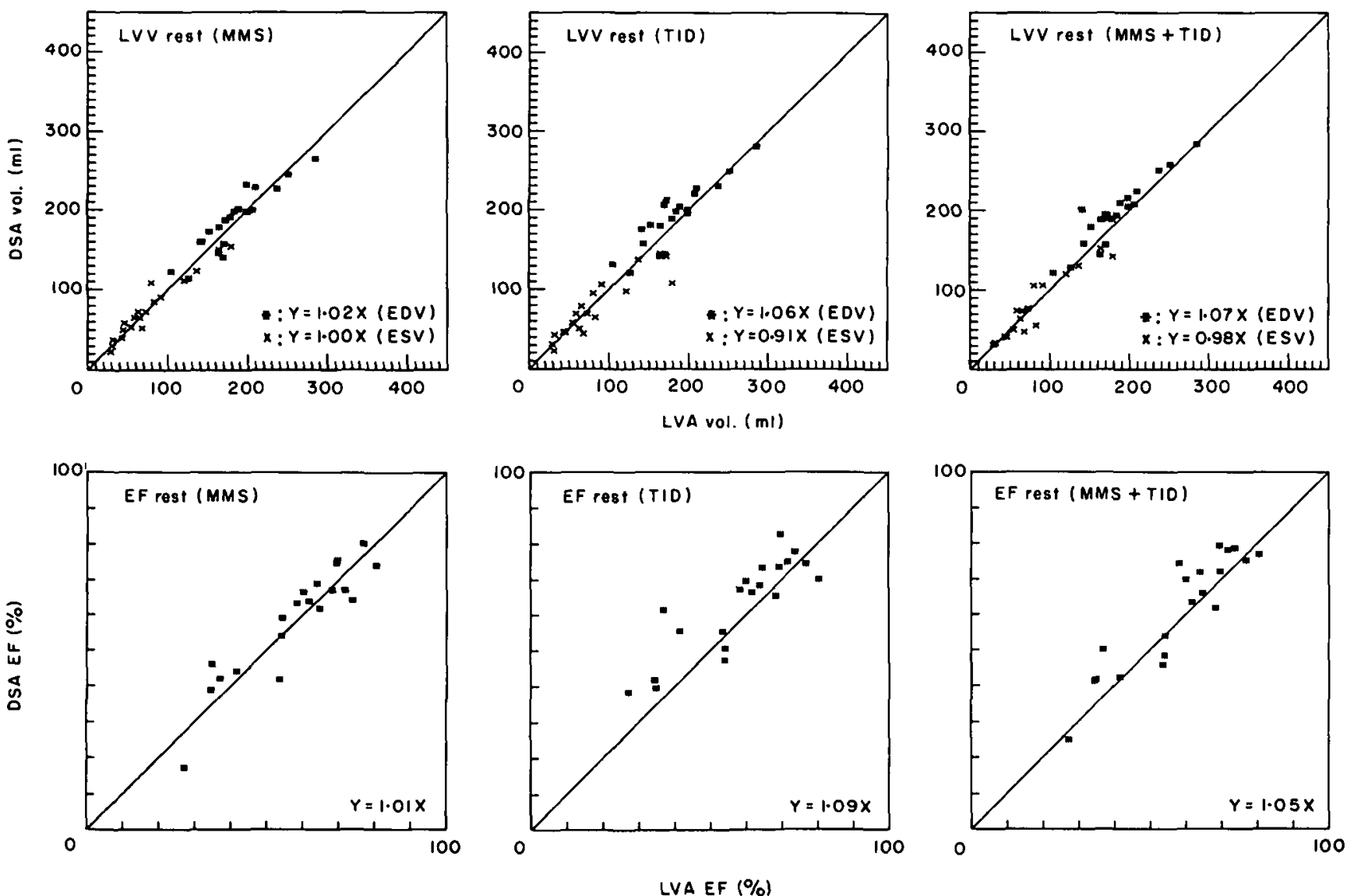

Figure 5 Linear regression analysis for volumetric data at rest (LVV - left ventricular volume, EDV — end-diastolic volume, ESV - end-systolic volume, EF- ejection fraction, LVA - left ventricular angiocardiography, DSA - digital subtraction angiocardiography, solid line - line of identity). 

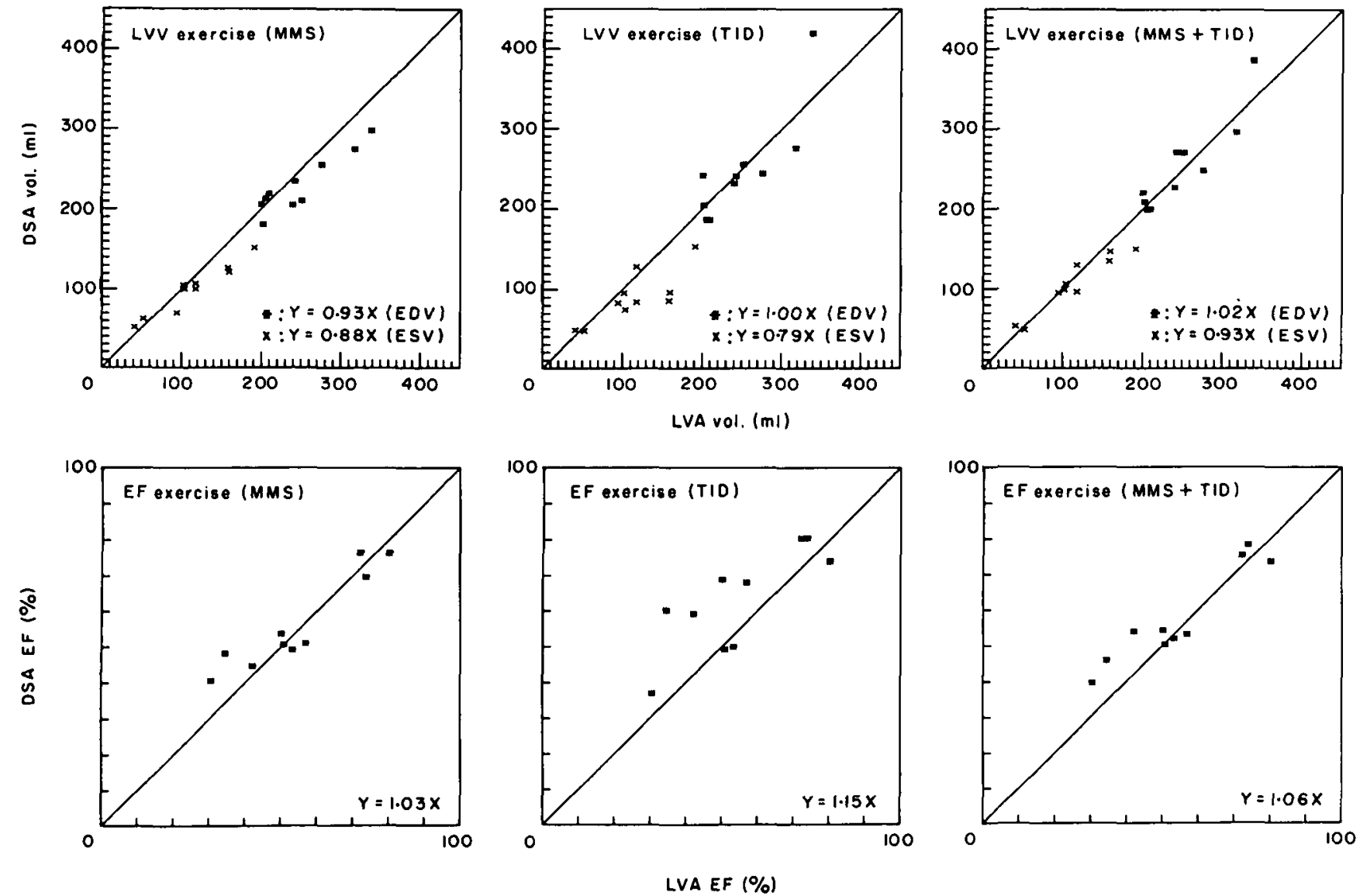

Figure 6 Linear regression analysis for volumetric data during exercise (abbreviations as in Fig. 5). 
Table 2 Correlation coefficients ( $r$ ) and standard error of the mean (SEE) for 20 patients at rest. Volumes are obtained by intravenous digital angiocardiography and compared to left ventricular angiocardiography

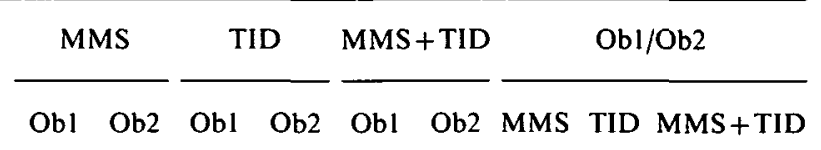

\begin{tabular}{llccccccccccc}
\hline EDV: & $r$ & 0.915 & 0.911 & 0.903 & 0.900 & 0.922 & 0.919 & 0.988 & 0.969 & 0.984 \\
& SEE \% & 10 & 10 & 11 & 11 & 10 & 10 & 3 & 6 & 4 \\
ESV: & $r$ & 0.967 & 0.975 & 0.912 & 0.948 & 0.950 & 0.984 & 0.974 & 0.946 & 0.975 \\
& SEE \% & 15 & 13 & 22 & 20 & 18 & 11 & 13 & 21 & 14 \\
EF: & $r$ & 0.918 & 0.915 & 0.857 & 0.905 & 0.912 & 0.962 & 0.930 & 0.888 & 0.954 \\
& SEE \% & 11 & 12 & 15 & 12 & 12 & 8 & 10 & 11 & 8 \\
\hline
\end{tabular}

EDV - end-diastolic volume, ESV - end-systolic volume, EF - ejection fraction.

Obl - observer 1, Ob2 - observer 2.

Table 3 Correlation coefficients ( $r$ ) and standard error of the mean (SEE) for 10 patients during exercise. Volumes are obtained by intravenous digital angiocardiography and compared to left ventricular angiocardiography (Abbreviations as in Table 2)

\begin{tabular}{|c|c|c|c|c|c|c|c|c|c|c|}
\hline & & \multicolumn{2}{|c|}{ MMS } & \multicolumn{2}{|c|}{ TID } & \multicolumn{2}{|c|}{$\mathrm{MMS}+\mathrm{TID}$} & \multicolumn{3}{|c|}{$\mathrm{Ob} 1 / \mathrm{Ob} 2$} \\
\hline & & Obl & $\mathrm{Ob} 2$ & $\mathrm{Obl}$ & Ob2 & $\mathrm{Ob} 1$ & $\mathrm{Ob} 2$ & MMS & TID & MMS + TID \\
\hline EDV: & $\begin{array}{l}r \\
\text { SEE } \%\end{array}$ & $\begin{array}{c}0.920 \\
7\end{array}$ & $\begin{array}{c}0.917 \\
9\end{array}$ & $\begin{array}{c}0.843 \\
15\end{array}$ & $\begin{array}{c}0 \cdot 810 \\
13\end{array}$ & $\begin{array}{c}0 \cdot 910 \\
10\end{array}$ & $\begin{array}{c}0.926 \\
8\end{array}$ & $\begin{array}{c}0.819 \\
13\end{array}$ & $\begin{array}{c}0.977 \\
6\end{array}$ & $\begin{array}{c}0.961 \\
6\end{array}$ \\
\hline ESV: & $\begin{array}{l}r \\
\text { SEE } \%\end{array}$ & $\begin{array}{c}0.964 \\
12\end{array}$ & $\begin{array}{c}0.936 \\
15\end{array}$ & $\begin{array}{c}0.807 \\
19\end{array}$ & $\begin{array}{c}0.855 \\
20\end{array}$ & $\begin{array}{c}0.952 \\
13\end{array}$ & $\begin{array}{c}0.945 \\
13\end{array}$ & $\begin{array}{c}0.948 \\
12\end{array}$ & $\begin{array}{c}0.819 \\
26\end{array}$ & $\begin{array}{c}0.959 \\
11\end{array}$ \\
\hline EF: & $\begin{array}{l}r \\
\text { SEE \% }\end{array}$ & $\begin{array}{c}0.933 \\
13\end{array}$ & $\begin{array}{c}0.933 \\
11\end{array}$ & $\begin{array}{c}0.792 \\
22\end{array}$ & $\begin{array}{c}0 \cdot 792 \\
20\end{array}$ & $\begin{array}{c}0 \cdot 936 \\
13\end{array}$ & $\begin{array}{c}0.920 \\
13\end{array}$ & $\begin{array}{c}0.958 \\
8\end{array}$ & $\begin{array}{c}0.772 \\
16\end{array}$ & $\begin{array}{c}0.974 \\
6\end{array}$ \\
\hline
\end{tabular}

has been performed for left ventricular ejection fraction $^{[14]}$ with a correlation coefficient of $r=0.83$. This correlation is lower than ours because there was an average time difference of 42 days between the two examinations and the radionuclide reference method has a consistently lower resolution than conventional cineangiocardiography.

In the literature, two basic subtraction modes have been proposed, namely the mask mode subtraction $\left(\mathrm{MMS}^{[8-12\}}\right)$ and the time interval difference (TID $\left.{ }^{[112]}\right)$. We decided to compare these two subtraction modes for studying left ventricular function at rest and during exercise. Both methods have advantages and limitations: MMS subtraction produces images which are similar to conventional left ventricular angiocardiograms and therefore easy to interpret but it is very sensitive to patient motion. TID imaging is almost insensitive to slow respiratory motion and produces a good contrast for the fast moving ventricular wall but it fails to detect local hypokinetic regions. Therefore, we combined both techniques in order to optimize contour detection, the MMS + TID method.

At rest, all three methods show reasonably good results although the lowest correlation coefficients and the highest SEE were observed for the TID method. This is probably due to the fact that hypoand akinetic regions in patients with coronary artery disease are responsible for low contrast TID images. This becomes more evident during exercise when correlation coefficients were considerably lower for the TID than the other two methods. The MMS and MMS + TID methods showed equally good results at rest and during exercise although the MMS+TID method tended to have slightly 

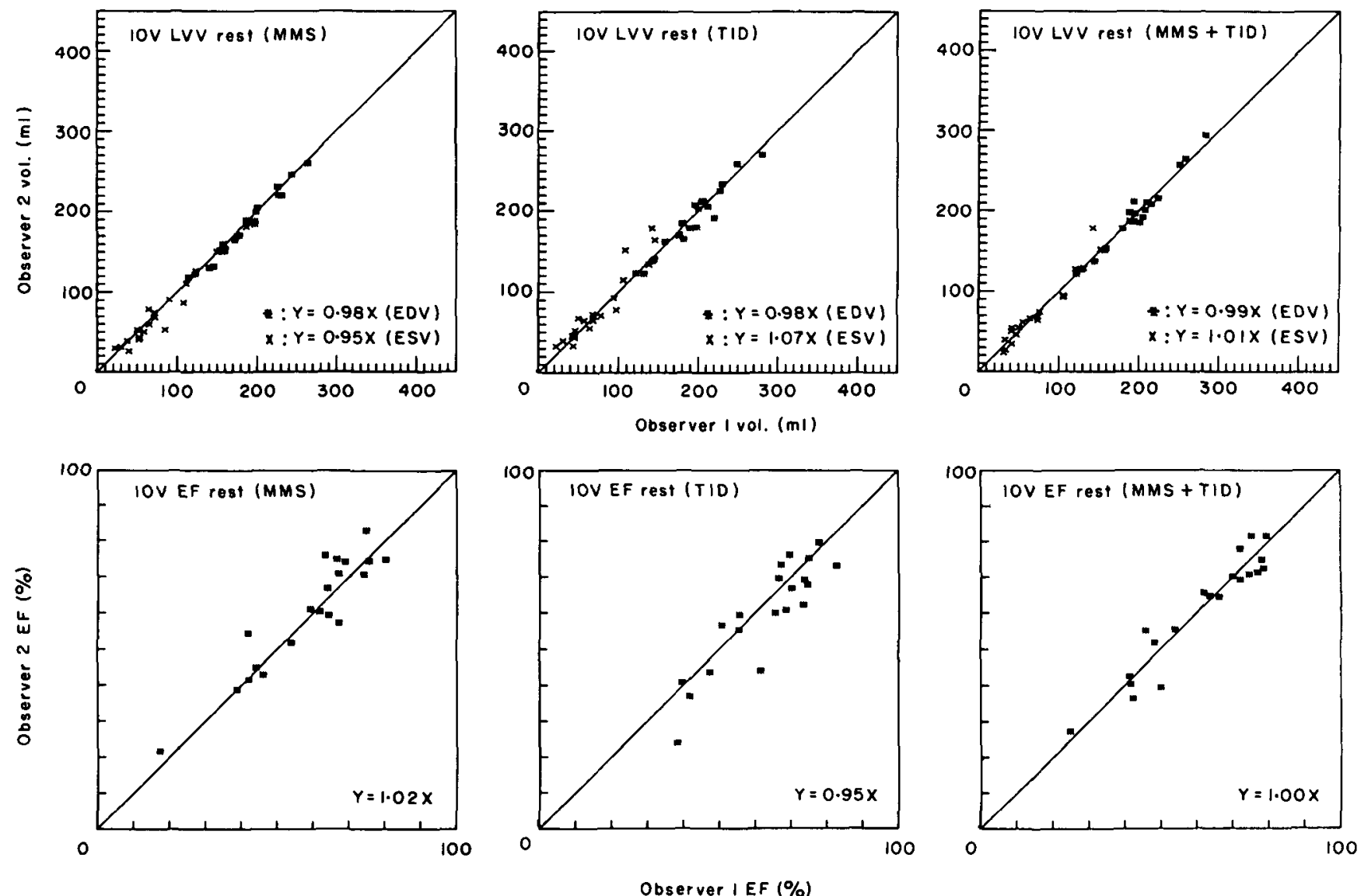

Figure 7 Interobserver variability (IOV): Resting data (abbreviations as in Fig. 5). 

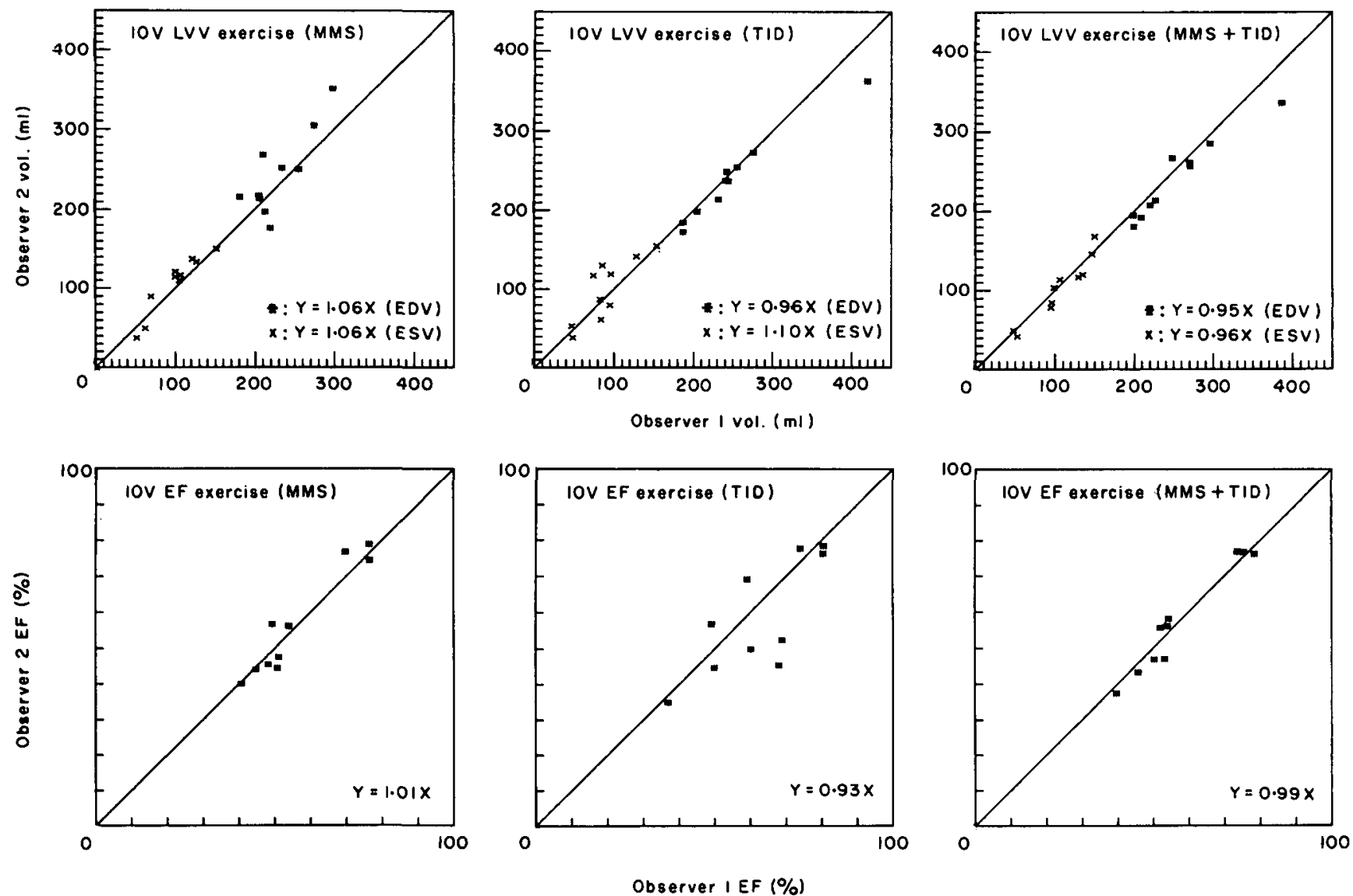

Figure 8 Interobserver variability (IOV): Exercise data (abbreviations as in Fig. 5). 
Table 4 Data from the literature for the comparison of volumes determined with digital subtraction angiocardiography and with conventional cineangiocardiography. All patients were studied at rest and the subtraction technique was mask mode subtraction

\begin{tabular}{|c|c|c|c|c|c|c|}
\hline & \multicolumn{2}{|c|}{ EDV } & \multicolumn{2}{|c|}{ ESV } & \multicolumn{2}{|c|}{$\mathbf{E F}$} \\
\hline & $n$ & $r$ & $n$ & $r$ & $n$ & $r$ \\
\hline Felix et al. ${ }^{[1]}$ & 46 & 0.98 & 46 & 0.93 & 46 & 0.94 \\
\hline Kronenberg et al. ${ }^{[2]}$ & 18 & 0.91 & & & 9 & 0.89 \\
\hline Lauber et al. ${ }^{[3]}$ & 20 & $0.96^{*}$ & & & & \\
\hline Nichols et al. ${ }^{[4]}$ & 28 & 0.97 & 28 & 0.97 & 28 & 0.97 \\
\hline Nissen t $_{\text {al. }}^{[5]}$ & 40 & 0.88 & 40 & 0.92 & 40 & 0.93 \\
\hline Norris et al. ${ }^{[6]}$ & 26 & 0.88 & 26 & 0.89 & 26 & $0 \cdot 81$ \\
\hline Tobis el al..$^{[7]}$ & 27 & 0.82 & 27 & 0.93 & 27 & 0.96 \\
\hline Our data & 20 & 0.92 & 20 & 0.97 & 20 & 0.92 \\
\hline
\end{tabular}

*End-diastolic and end-systolic volumes are combined into one data set.

better correlation coefficients than the MMS method alone. Also the two observers judged the MMS + TID method to be the most convenient technique since it was usually very helpful for the observer to define the left ventricular contour from the two different types of subtracted images. This is most important during exercise when patient motion (respiration) becomes inevitable and the MMS method is affected by motion artifacts whereas the TID method remains interpretable.

A major benefit of digital subtraction angiocardiography is that it is less invasive and does not induce arrhythmias which is especially important during exercise. Another advantage is the possibility of assessing left ventricular function during exercise which has so far only been possible with nuclear imaging techniques or echocardiography. Assessment of left ventricular volumes by radionuclide ventriculography has been validated at rest $^{[17-22]}$. The studies showed a good correlation mainly between the count-based methods of radionuclide ventriculography and conventional angiocardiography. There are several problems with quantitative radionuclide angiography: accurate calibration is difficult, there are superposition problems with the left atrium in the left anterior oblique (LAO) position, the basic resolution is inferior to angiocardiography and long acquisition times are affected by respiratory artifacts. The accuracy of the estimation of left ventricular ejec- tion fraction by 2D-echocardiography is generally satisfactory ${ }^{[23-25]}$ but systematic underestimation of left ventricular volume up to $40 \%{ }^{[23]}$ remains a basic problem. The estimation of left ventricular volume by echocardiography becomes much more difficult during exercise when respiratory motions interfere with adequate echocardiographic recordings. Several other problems limit echocardiographic volume determination: only in a minority of patients is it possible to record the true apex of the left ventricle due to the anatomic limitations (echo-window), 2D-echocardiography provides only a tomographic section of the left ventricle (and not the maximal outer border as with angiocardiography) and temporal as well as spatial resolution is inferior to angiocardiography.

Thus, digital subtraction angiocardiography appears to be superior to radionuclide ventriculography and echocardiography with regard to temporal and spatial resolution and accuracy of left ventricular volume determination during exercise. Possible drawbacks of digital subtraction angiography are motion artifacts at high work loads; furthermore, repeated contrast agent injection may change basic haemodynamics per se in contrast to radionuclide ventriculography or echocardiography. The reported data are limited to one angiographic projection (RAO) which might be problematic in some patients with posterior asynergic regions. However, future applications of digital subtraction angiocardiography will possibly include the LAO projection as well when special subtraction modes solve the problem of left atrial overlap.

The costs are a difficult factor to evaluate. They are comparable to those involved with stress radionuclide ventriculography. Because the examination procedure is similar to conventional angiocardiography the personnel and installations of the catheterization laboratory can be used without additional expenditure during free hours between routine examinations. The costs for our digital image processing system range from $\$ 70000$ to $\$ 80000$. The currently used system is very versatile and is also used for other image processing applications at our institute.

In summary, we can conclude that digital subtraction cineangiocardiography allows accurate determination of left ventricular function both at rest and during exercise. The combination of mask mode subtraction and time interval difference seems to be the best subtraction technique for left ventricular contour detection. 


\section{References}

[1] Felix R, Eichstaedt H, Kempter $\mathrm{H}$ et al. A comparison of conventional contrast ventriculography and digital subtraction ventriculography. Clin Cardiol 1983; 6: $265-76$.

[2] Kronenberg HW, Price RR, Smith $\mathrm{CW}$ et al. Evaluation of left ventricular performance using digital subtraction angiography. Am J Cardiol 1983; 51: $837-42$.

[3] Lauber A, Fischbach T, Jehle J et al. Digital subtraction angiocardiography: accuracy of determination of left ventricular volumes using intravenous injection of contrast medium. Z. Kardiol 1983; 72: 262-7.

[4] Nichols AB, Martin EC, Fles TP et al. Validation of the angiographic accuracy of digital left ventriculography. Am J Cardiol 1983; 51: 224-30.

[5] Nissen SE, Booth D, Waters J, Fassas T, DeMaria AN. Evaluation of left ventricular contractile pattern by intravenous digital subtraction ventriculography: comparison with cineangiography and assessment of interobserver variability. Am J Cardiol 1983; 52: 1293-8.

[6] Norris SL, Slutsky RA, Mancini GJ et al. Comparison of digital intravenous ventriculography with direct left ventriculography for quantitation of left ventricular volumes and ejection fractions. Am J Cardiol 1983; 51 : 1399-403.

[7] Tobis J, Nacioglu O, Johnston WD et al. Left ventricular imaging with digital subtraction angiography using intravenous contrast injection and fluoroscopic exposure levels. Am Heart J. 1982; 104: 20-7.

[8] Vas R, Diamond GA, Forrester JS, Whiting JS, Swan HJC. Computer enhancement of direct and venousinjected left ventricular contrast angiography. Am Heart J 1981: 102; 719--28.

[9] Brennecke R, Brown TK, Buersch J, Heintzen PH. Digital processing of videoangiocardiographic image series using a minicomputer. In: Computers in cardiology. St. Louis, 1976: 255-260.

[10] Brody WR. Digital subtraction angiography. IEEE Trans Nuc Sci 1982; 29: 1176-80.

[11] Kruger RA, Mistretta CA, Houk TL et al. Real-time computerized fluoroscopic cardiac imaging. In: Noninvasive cardiovascular measurements. Proc SPIE, 1978; 167: 77-82.

[12] Shaw CG, Ergun DL, Kruger RA et al. Intravenous angiography using computerized fluoroscopy. IEEE Trans Nuc Sci 1980; 27: 1042-6.
[13] Spiller P, Fischbach T, Jehle J et al. Reliability of digital subtraction angiocardiography for the estimation of left ventricular function during exercise. $Z$ Kardiol 1983; 72: 681-7.

[14] Goldberg HL, Moses JW, Borer JS et al. Exercise left ventriculography utilizing intravenous digital angiography. J Am Coll Cardiol 1983; 2: 1092-8.

[15] Henrici P. Essentials of numerical analysis. New York: John Wiley, 1982: 260-74.

[16] Sandler H, Dodge HT. Angiographic methods for determination of left ventricular geometry and volume. In: Mirsky I, Ghista DN, Sandler H, eds. Cardiac mechanics. New York: John Wiley, 1974: 14I-70.

[17] Dehmer GJ, Firth BG, Lewis SE, Willerson JT, Hillis LD. Direct measurement of cardiac output by gated equilibrium blood pool scintigraphy: validation of scintigraphic volume measurements by a nongeometric technique. Am J Cardiol 1981; 47: 1061-7.

[18] Dehmer GJ, Firth BG, Hillis LD et al. Alterations in left ventricular volumes and ejection fraction at rest and during exercise in patients with aortic regurgitation. Am J Cardiol 1981; 48: 17-27.

[19] Slutsky R, Karliner J, Ricci D et al. Left ventricular volumes by gated equilibrium radionuclide angiography: a new method. Circulation 1979; 60: 556-64.

[20] Massie BM, Kramer BL, Gertz EW, Henderson SG. Radionuclide measurements of left ventricular volume: comparison of geometric and counts-based methods. Circulation 1982; 65: 725-30.

[21] Parrish MD, Graham TP, Born ML, Jones JP, Boncek RJ, Partain CL. Radionuclide ventriculography for assessment of absolute right and left ventricular volumes in children. Circulation 1982; 66: 811-19.

[22] Maurer AH, Siegel JA, Denenberg BS et al. Absolute left ventricular volume from gated blood pool imaging with use of esophageal transmission measurement. Am J Cardiol 1983; 51:853-8.

[23] Carr KW, Engler RL, Forsythe JR, Johnson AD, Gosink B. Measurement of left ventricular ejection fraction by mechanical cross-sectional echocardiography. Circulation 1979; 59: 1196-206.

[24] Schiller NB, Acquatella H, Ports TA et al. Left ventricular volume from paired biplane two-dimensional echocardiography. Circulation 1979; 60: 547-55.

[25] Jenni R, Vieli A, Hess O, Anliker M, Krayenbuehl HP. Estimation of left ventricular volume from apical orthogonal 2-D echocardiograms. Eur Heart J 1981; 2: 217-25. 